\title{
Research on the Physical Properties of Calcium Sulfate Whisker and the Effects of its Addition on Paper and its Printing Performance
}

\section{Haitang Liu (D85390688@qq.com )}

Tianjin University of Science and Technology https://orcid.org/0000-0001-7910-1637

Jing Liu

Tianjin University of Science and Technology

\section{Yongzhen An}

Tianjin University of Science and Technology

Jie Li

Tianjin University of Science and Technology

\section{Xuexiu Li}

Tianjin University of Science and Technology

\section{Xin Jin}

Tianjin University of Science and Technology

\section{Lin Chen}

Tianjin University of Science and technology

\section{Yujie Gao}

Tianjin University of Science and technology

\section{Zhenhua Lu}

Tianjin University of Science and technology

\section{Chuanling Si}

Tianjin University of Science and technology

\section{Research Article}

Keywords: Calcium Sulfate Whisker, Paper filler, Properties of paper, Printing performance of paper

Posted Date: February 16th, 2021

DOI: https://doi.org/10.21203/rs.3.rs-183871/v1

License: (c) (1) This work is licensed under a Creative Commons Attribution 4.0 International License. Read Full License 
Version of Record: A version of this preprint was published at Nordic Pulp \& Paper Research Journal on November 9th, 2021. See the published version at https://doi.org/10.1515/npprj-2021-0042. 


\section{Abstract}

In this investigation, softwood pulp and bleached wheat straw pulp were used as raw materials, and Calcium Sulfate Whiskers (CSW) were used as fillers. Based on the structural properties and characteristics of CSW, the printing properties of the paper with CSW, such as whiteness, opacity, pH value, uniformity, Z-direction tensile strength and surface strength, were analyzed. The results showed that CSW has low solubility, high retention rate and fiber-like appearance. The whiteness of the paper is the best when the filling amount of CSW is $20 \%$. The paper opacity of softwood pulp increases significantly, and the opacity of bleached wheat straw pulp decreases significantly when CSW is more than $30 \%$. The addition reduces $\mathrm{pH}$ and surface strength of the paper. The evenness of the paper does not change obviously. The Z-direction tensile strength of the paper decreases in the softwood paper, but increases obviously in the bleached wheat straw paper.

Graphic abstract

\section{Introduction}

The contribution of papermaking filling is to reduce production costs and obtain certain properties of the paper, such as filling the gaps in the paper (The filling methods are shown in Fig. 1), improving the evenness of the paper, increasing the whiteness and opacity of the paper, improving the printability and increasing the dimensional stability of the paper, and etc (Zhu et al. 2005). At present, fillers commonly used in the paper industry mainly include talc (Liu et al., 2010; Chainarong et al., 2018), calcium carbonate (Wu et al. 2016; Rajamuneeswaran et al. 2020), kaolin (Gendy et al. 2014), titanium dioxide (Gu. 2019; Ketegenov et al. 2019), and so on. Wu and others discussed the physical properties of shell powder (Wu. 2016), wet end performance, and paper filling performance. The feasibility and advantages of shell powder are analyzed by comparing with the properties of light calcium carbonate. Rui started with the research on the effect and feasibility of attapulgite hydration pretreatment (Rui. 2012), organic and inorganic modification on the performance of filled paper products. Chang adds wollastonite to the wet end of papermaking (Chang. 2014). It can not only save plant fiber raw materials, reduce the felling of trees, but also improve the optical properties such as opacity and hiding power of the paper to a certain extent. Furthermore,appropriately improve its physical strength index within the allowable range of the paper.

In recent years, with the depletion of mineral resources and rapid economic development in China. Using solid waste to prepare low-cost green fillers, such as Calcium Sulfate Whisker (CSW), has become a new direction for the development of paper fillers. Phosphogypsum whiskers, Calcium Sulfate Whiskers (CSW), also known as calcium sulfate microfibers. It is a fibrous single crystal of calcium sulfate with high strength, high modulus, high dielectric strength, abrasion resistance, high temperature resistance, corrosion resistance, good infrared reflectivity, easy surface treatment, easy compounding with polymers, non-toxic and many other excellent physical and chemical properties. It is not only a relatively high-grade reinforced component in the existing composite materials, but also an inorganic material whose high cost 
performance attracts many researchers (Shi et al. 2000). 0-70\% wood pulp or straw pulp has been replaced for papermaking by whiskers which made of gypsum by-product generated from the phosphoric acid wet production process by Mao and others (Mao. 2006). Chen and others fixed the wood fiber content of $2.5 \mathrm{~g}$ and added different amounts of Calcium Sulfate whiskers without any additives (Chen et al. 2007). It has been concluded that the whiteness of the paper increases obviously with the increase of the proportion of gypsum whiskers in the paper. However, the increasing trend of paper whiteness slows down when the content of gypsum whisker reaches a certain proportion.

The citation reports the application of commonly used fillers in the paper industry. The strength, bulk and stiffness of the paper are affected easily by the increase of filling amount negatively, and the phenomenon of hair loss and powder loss occur commonly during the printing process. Therefore, the related researches based on reducing or avoiding such negative effects have a very broad prospect (Shen et al. 2007). In this study, the characteristics of reinforcing fibers and ultra-fine inorganic fillers of CSW were used to fill softwood pulp and bleached wheat straw pulp for papermaking (Lu et al. 2010). The influence of CSW as a papermaking filler on the paper printing performance is analyzed. In order to obtain the best paper printing performance in this study, it is necessary to find the filling amount of CSW, which is helpful to the paper industry, printing industry and environmental protection (Su. 2003).

\section{Experimental}

\subsection{Raw materials}

Coniferous wood pulp board and bleached wheat straw pulp are provided by Shandong Tranlin Group CSW is provided by Henan Luoyang Liangdong non-metallic Metal Material Technology Development Co., Ltd.

\subsection{Experimental methods.}

\subsubsection{Properties of CSW}

(1) Morphological parameters of CSW

The $0.04 \mathrm{~g}$ absolute dry weight CSW was placed in a clean glass bottle with glass beads,and the right amount of distilled water was added to mix it up fully. Then the 912 Fiber analyzer was used to measure the length, width, aspect ratio and length distribution frequency of CSW.

(2) Whiteness of CSW

Firstly, the CSW was placed in a petri dish and dried in 201 Electric constant temperature drying box (105 ${ }^{\circ} \mathrm{C}$ ) for more than 4 hours, then transferred to the dryer to cool 30 min. Finally, an appropriate amount of CSW was taken for tablet pressing treatment, afterwards, the whiteness of the whisker was measured by Model 970894 spectrophotometer(Lorentzena \& Wettre). Generally, 4 to 6 different test points were measured, and the arithmetic mean value was taken as the whiteness value of the whisker. 
(3) Solubility and electrical conductivity of CSW

First, $2 \mathrm{~g}$ of absolute dry CSW was weighted using bl-320h electronic balance (Shimadzv, Japan) and dissolved with distilled water in a clean beaker to make a $1 \%$ concentration suspension at room temperature for more than $6 \mathrm{~h}$. Then filter the CSW suspension and use a small beaker to take an appropriate amount of filtrate for conductivity measurement. In addition, the filtrate was put in a weighing bottle (clean and constant weight) and placed in a constant temperature drying box $\left(105 \pm 2{ }^{\circ} \mathrm{C}\right)$ for more than $12 \mathrm{~h}$. Finally, it is transferred to the dryer to cool down $30 \mathrm{~min}$ and weighed. The solubility of CSW is calculated according to the following formula:

$$
s=\frac{m_{3}-m_{1}}{m_{2}-m_{3}} \times 100 \%
$$

\section{Note}

$m_{1}$-weighing bottle mass, $g$.

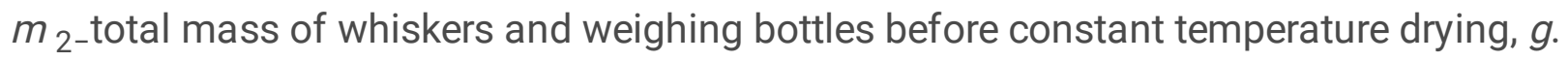

$m_{3-}$ total mass of filtrate and weighing bottle after constant temperature drying, $g$.

(4) Zeta potential of CSW

$1 \mathrm{~g}$ of absolute dry mass CSW was placed in a clean and dry beaker and prepared a $1 \%$ concentration suspension with distilled water. The Zeta potential value was recorded when the slurry suspension formed a stable packing plug without rise anymoreafter the vacuum pump of the Szp06 Zeta potentiometer (Mutek Analytic $\mathrm{GmbH}$ ) started.

(5) Fourier transform Infrared Spectroscopy of CSW

The samples of CSW and potassium bromide were put in a constant temperature drying box $\left(105 \pm 2{ }^{\circ} \mathrm{C}\right)$ and dried for more than $4 \mathrm{~h}$ until completely dry. Then the samples of CSW and potassium bromide was transfered to the dryer for $30 \mathrm{~min}$. The mixture of CSW and potassium bromide was ground in a mortar for 5 min uniformly according to the ratio of 1:100, and then treated with tablet pressing (pressure 10 Mpa, tablet time $1 \mathrm{~min}$ ) for analysis.

(6) Scanning electron microscope observation

The surface morphology of CSW was observed by SEM electron microscope with magnification of 1000 .

\subsubsection{Defibering and beating}

The softwood pulp board and bleached wheat straw pulp were weighed $360 \mathrm{~g}$ respectively and torn into pieces of $25 \mathrm{~mm} \times 25 \mathrm{~mm}$. Soaked in $5 \mathrm{~L}$ water for $4 \mathrm{~h}$ and beaten with ZQS2-23 Valley beater, 
Northwest Light Industry Institute Machinery Plant. The coniferous wood pulp board was beaten to 30 ${ }^{\circ} \mathrm{SR}$ of beating degree. The pulp consistency was controlled at about $1.57 \%$. The lever arm load was controlled at $117 \mathrm{~N}$. The bleached wheat straw pulp was beaten to $30^{\circ} \mathrm{SR}$. The pulp consistency was controlled at about $1.57 \%$. The lever arm load was controlled at $90 \mathrm{~N}$.

\subsubsection{Determination of fiber length distribution frequency}

CSW, softwood pulp and bleached wheat straw pulp with an absolute dry mass of $0.04 \mathrm{~g}$ were weighed respectively. After beating, it was determined by fiber analyzer.

\subsubsection{Making of handsheets}

The $80 \mathrm{~g} \mathrm{~m}^{-2}$ handsheets were made by adding different amount of CSW in the 7407.S Standard Sheet Former (Mavis Company, UK), and the control sample was made at the same time. According to GB/T $10739 \sim 1989$, the handsheets were placed at $23 \pm 2{ }^{\circ} \mathrm{C}$ and $50 \% \mathrm{RH} \pm 5^{\circ} \mathrm{C}$ environment for $4 \mathrm{~h}$.

\subsubsection{Testing of physical properties of paper}

(1) Retention rate of CSW

The retention rate of CSW was measured by ash burning method according to GB/T $742 \mathrm{Mel} 2008$. The samples of CSW was carbonized and burned in a high temperature furnace at $900{ }^{\circ} \mathrm{C}$, the loss of CSW was ignored.

Retention rate of $\mathrm{CSW}=\frac{\mathrm{m}}{\mathrm{J}} \times 100 \%$

Where $\mathrm{m}$ is the ash content of CSW $\left(\mathrm{g} \mathrm{m}^{-2}\right) ; M$ is the amount of CSW added $\left(\mathrm{g} \mathrm{m}^{-2}\right)$.

(2) Detection of paper whiteness

Different amounts of CSW were added to softwood pulp and bleached wheat straw pulp respectively. The whiteness of the handmade paper was measured by spectrophotometer. Generally 4-6 different test points were measured and taken average as the whiteness of the paper.

(3) Detection of paper opacity

According to GB/T 1543-2005 method, the opacity of hand-coated tablets was measured.

(4) Testing of paper acidity and alkalinity

The acidity and alkalinity of paper wer determined taccording to GB/T 1545.2-2003 using PHS-3C acidity meter (Jiangsu Jintan Hengfeng instrument Factory). The $\mathrm{pH}$ of the paper was measured by the cold water leaching method. $3 \mathrm{~g}$ (permanently dry) paper was cut into wide pieces with $1 \mathrm{~cm}$, soaked in 1000 
$\mathrm{mL}$ of distilled water for $1 \mathrm{~h}$, and the $\mathrm{pH}$ value of the dipping solution with was measured with a $\mathrm{pH}$ meter every $1 \mathrm{~h}$, three data were recorded, and taken average finally.

(5) Determination of paper uniformity

The evenness of the handsheets after proper pressing (2571-1 Wet paper sheet press, Kumagai Rikikogyo Co., Ltd.) and drying was measured by LPA070 evenness tester of opTest Equipment Inc.

(6) Detection of Z-direction tensile strength of paper.

The prepared softwood handsheet and bleached wheat straw handsheet were cut into 10 pieces in the Zdirection by FQ-Q2D15 paper cutter (Sichuan Changjiang Papermaking Instrument Co.) and Ltd.FQ KTD300 adjustable distance paper cutter (Sichuan Changjiang Papermaking Instrument Co.). The Zdirection tensile strength of the handsheet was measured using a Z-direction tensile strength tester.

(7) Detection of paper surface strength

The surface strength of paper was tested using RI printability tester. Test conditions: The printing speed is set to $60 \mathrm{r}$, and the ink filling time for $0.5 \mathrm{~mL}$ of ink is $3 \mathrm{~min}$.

\section{Results And Discussion}

\subsection{Main physical properties of CSW}

\subsubsection{The morphological parameters of CSW and its length distribution frequency.}

The analysis results of morphological parameters of CSW are as below, the Number average length is $0.713 \mathrm{~mm}$, Form factor is $87.8 \%$, Kink index is $1.357 \%$.

The weight average length of CSW is $1.239 \mathrm{~mm}$ (Double average length $1.976 \mathrm{~mm}$ ), which is longer than that of non-wood plant fiber and close to that of softwood fiber. Aspect ratio is an important standard to evaluate the pulping and papermaking value of raw fiber. In general, the fiber aspect ratio of pulping and papermaking raw materials is low and less than 45 . The aspect ratio of CSW is 89 . Referring to the main technical standard of gypsum fiber formulated by China University of Mining and Technology (Yin et al. 2008), the CSW used here should be calcium sulfate medium long whisker, which provides more opportunities for contacting and cross-linking with plant fibers. It can be concluded from the form factor and kink index of CSW that, CSW is an inorganic mineral fiber, not straight, but shows a certain bending shape. The chance of mechanical entanglement with the plant fiber increases when CSW is added to the plant fiber, which may be very beneficial to the paper strength and filler retention. The length distribution of different fibers is shown in Table 1. 
Table 1

The length distribution frequency of different fibers (Lu et al. 2010)

\begin{tabular}{|llll|}
\hline$L / \mathrm{mm}$ & \multicolumn{2}{l|}{ Proportion/\% } & \\
\cline { 2 - 4 } & Softwood pulp & Wheat straw pulp & CSW \\
\hline$L<0.5$ & 17.8 & 43.1 & 21.5 \\
\hline $0.5 \leq L \leq 1.0$ & 27.8 & 35.1 & 33.4 \\
\hline $1.0 \leq L \leq 1.5$ & 21.4 & 15.6 & 15.2 \\
\hline $1.5 \leq L \leq 2.0$ & 14.4 & 4.9 & 11.2 \\
\hline $2.0 \leq L \leq 2.5$ & 9.0 & 1.0 & 7.0 \\
\hline
\end{tabular}

It can be seen that the length of CSW accounts for the largest proportion in the range of $0.5-1.0 \mathrm{~mm}$, reaching $33.4 \%$. The proportion below $0.5 \mathrm{~mm}$ is also relatively large, reaching $21.5 \%$. The proportion within the range of $1.0-1.5 \mathrm{~mm}, 1.5-2.0 \mathrm{~mm}$ and $2.0-2.5 \mathrm{~mm}$ fall to $15.2 \%, 11.2 \%$ and $7 \%$, respectively. The above data show that the morphological characteristics of medium-long fibers of CSW is basically consistent with those of papermaking plant fibers, especially non-wood plants. As an inorganic fiber, CSW with special morphology and structure not only has the filling property of particles in the papermaking process, but also can improve the smoothness, opacity, whiteness, printability and other properties of the paper. It can also partially replace the plant fiber on the premise of maintaining the paper strength basically, reduce the consumption of plant fiber and save the cost.

\subsubsection{Zeta potential, conductivity, pH value, whiteness and solubility of CSW}

Table 2

Zeta, conductivity and $\mathrm{pH}$ of CSW

\begin{tabular}{|c|c|c|c|c|c|c|}
\hline CSW & $\begin{array}{l}\text { Mass } \\
\text { fraction /(\%) }\end{array}$ & $\begin{array}{l}\text { Zeta potential } \\
/(\mathrm{mv})\end{array}$ & $\begin{array}{l}\text { Electric conductivity } \\
/(\mathrm{ms} / \mathrm{cm})\end{array}$ & $\mathrm{pH}$ & $\begin{array}{l}\text { Whiteness } \\
/ \%\end{array}$ & $\begin{array}{l}\text { Solubility } \\
\text { g/100g } \\
\text { water }\end{array}$ \\
\hline & 0.25 & -10.0 & 2.39 & 7.08 & \multirow[t]{3}{*}{98} & \multirow[t]{3}{*}{0.33} \\
\hline & 0.50 & -7.3 & 2.52 & 6.88 & & \\
\hline & 1.00 & -5.6 & 2.75 & 6.50 & & \\
\hline
\end{tabular}

It can be seen from Table 2 that the Zeta potential and conductivity increase gradually, while the $\mathrm{pH}$ value decreases with the increase of the mass fraction of CSW. Zeta potential, one of the key parameters, is used to describe the wet-end charge characteristics of pulp suspensions (He et al. 1999). Theoretically, the closer the Zeta potential is to zero, the larger the mass fraction of CSW is. With the increase of electrical conductivity, the charge flow ability in CSW is enhanced, and the attraction between particles 
becomes greater. The plant fiber also shows a certain degree of negative electricity in water, so it is negative to the retention of CSW. In order to retain more CSW, it is not enough to rely on the combination of CSW with plant fibers, but also need to increase the amount of chemicals, such as cationic auxiliaries. In this way, the Zeta potential, conductivity and $\mathrm{pH}$ of the wet end system will be affected. If the conductivity value is too high, it will directly affect the normal use of the paper machine.

It can be seen that CSW has the characteristics of high whiteness like other paper fillers (such as talc, calcium carbonate and titanium dioxide), which is conducive to the improvement of paper whiteness. In terms of solubility, $0.33 \mathrm{~g} \mathrm{CSW} / 100 \mathrm{~g}$ water (Lu. 2010). The relatively high water solubility of CSW has an adverse effect on the retention and reinforcement of CSW. In addition, the water solubility of CSW will increase the concentration of $\mathrm{Ca}^{2+}$ in the wet end system of papermaking, and $\mathrm{Ca}^{2+}$ will be adsorbed on the surface of plant fibers, which is not conducive to the effective role of cationic functional auxiliaries.

\subsubsection{Scanning electron microscope of CSW}

Scanning electron microscope of CSW is shown in Fig. 2- (a) (b) (c) (d).

As shown in Fig. 2 (a), the CSW is obviously needle-like or rod-shaped under the scanning electron microscope. And the surface of the whisker is smooth and the size is relatively uniform. There are no obvious crystal defects such as cracks, and rarely granular whiskers. CSW belongs to hexagonal system. $\mathrm{Ca}^{2+}$ connects $\mathrm{SO}_{4}{ }^{2-}$ tetrahedron to form a layered structure on the [100] and [010] planes, as shown in Fig. 2 (b) (c). However, there is no layer on the [001] surface. From Fig. 2 (d), $\mathrm{Ca}^{2+}$ and $\mathrm{SO}_{4}{ }^{2-}$ are connected in a chain-like shape in the $\mathrm{C}$-axis direction, therefore the calcium sulfate whiskers are fibrous parallel to the C-axis. Between the chains, there is a channel with a diameter of $8 \AA(1 \AA=0.1 \mathrm{~nm})$, in which the crystal water is contained. The coordination number of $\mathrm{Ca}^{2+}$ is 6 , which is connected to 6 of the four adjacent $\mathrm{SO}_{4}{ }^{2-}$, and the crystal water is connected to $\mathrm{SO}_{4}{ }^{2-}$ by hydrogen bond (Freyer et al. 2003; Lv et al. 2013).

\subsubsection{Infrared Spectral Analysis of CSW}

In Fig. 3, there are stretching vibrational peaks of hydroxyl groups at $3610.09 \mathrm{~cm}^{-1}, 3550.31 \mathrm{~cm}^{-1}$ and $3490.53 \mathrm{~cm}^{-1}$. The front peaks are all produced by the crystalline water inside the whisker. The 3490.53 $\mathrm{cm}^{-1}$ is produced by the hydroxylation of calcium ions on the whisker surface. A very sharp asymmetric stretching vibration peak of hydroxyl group appeared at $1621.84 \mathrm{~cm}^{-1}$ (Shiel. 1979). $1153.22 \mathrm{~cm}^{-1}$, $659.54 \mathrm{~cm}^{-1}$ and $601.68 \mathrm{~cm}^{-1}$ are the absorption peaks of $\mathrm{SO}_{4}{ }^{2-}$. From the above peak analysis, it can be seen that there are $-\mathrm{OH}$ and $-\mathrm{SO}_{4}$ groups on the surface of CSW. According to the infrared spectrum, it can be considered the partial hydration reaction of CSW took place, and the water molecules entered into the interior to form crystalline water. At the same time, the surface also contains $-\mathrm{OH},-\mathrm{SO}_{4}$ groups, so that there is a certain electrostatic force. When CSW contacts with water, the active calcium ions on its surface will hydroxylate with aquatic products through electrostatic interaction, and the hydroxyl on the surface of CSW will also combine with water molecules by hydrogen bond. In this way, after the CSW added to 
the plant fiber, it will form not only a hydrogen bond with the plant fiber, but also a certain hydrogen bond, thus improving the strength of the paper.

\subsection{Effect of CSW filling on paper and printing properties}

\subsubsection{Retention rate of CSW}

Table 3

Retention of CSW for different pulps

\begin{tabular}{|lllllll|}
\hline Filling quantity/\% & $\mathbf{0}$ & $\mathbf{1 0}$ & $\mathbf{2 0}$ & $\mathbf{3 0}$ & $\mathbf{4 0}$ & $\mathbf{5 0}$ \\
\hline Retention (softwood pulp)/\% & 0 & 60.20 & 65.45 & 70.89 & 45.00 & 30.82 \\
\hline Retention (bleached wheat straw pulp)/\% & 0 & 58.43 & 60.83 & 71.45 & 40.96 & 20.24 \\
\hline
\end{tabular}

The retention rates of different pulps filled with CSW are shown in the Table 3 . The change law of filler retention is basically the same either CSW is filled with softwood pulp or bleached wheat straw pulp. The retention rate of fillers reaches the maximum when the filling amount is $30 \%$. And with the increase of the filling amount of CSW, the filler retention decreased gradually, that is the loss of CSW becomes more serious.

\subsubsection{Changes in whiteness and opacity of softwood pulp or bleached wheat straw pulp after adding CSW}

As shown in Fig. 4 (a), with the increase of CSW filling from $0-50 \%$, the whiteness of coniferous wood pulp and bleached wheat straw pulp showed the trend of increasing at first and then decreasing. When the filling amount was less than $20 \%$, the whiteness of the paper samples significantly increased. The maximum value of coniferous wood pulp and bleached wheat straw pulp reached $83.62 \%$ and $70.76 \%$ respectively at $20 \%$ filling amount. This is consistent with the change trend of the whiteness of the paper studied by Chen and others with the addition of gypsum whisker (Chen et al. 2006). Considering the physical properties of the filler, CSW is a kind of opalescent pigment whose whiteness is up to $98 \%$ and higher than that of the pulp (Yang et al. 2012). With the proper amount of filling, the whiteness of the paper could be improved. However, when the filling amount was $20 \%-50 \%$, the whiteness of the paper samples reduced significantly. Even at $50 \%$, the whiteness of the samples of the two different pulps was lower than that of the original paper. The water-soluble CSW increases the $\mathrm{Ca}^{2+}$ concentration in the wetend system of papermaking. The part of $\mathrm{Ca}^{2+}$ will be adsorbed on the surface of plant fibers, which reduces the retention of CSW, and some small particles of CSW are lost with white water. In the later stage, with the increase of the filling amount of CSW, the electrical conductivity (charge flow ability) of CSW increases, and the charge flow ability of Zeta potential diffusion layer is also enhanced. In this way, the binding ability of CSW is greater than that of fiber, and a large number of CSW flocculate with white water. In addition, the excessive addition of fillers will not only lead to poor bonding among fibers, but 
also increase the absorption in the range of visible light. The reflection under $457 \mathrm{~nm}$ are reduced, so that the whiteness of the paper is decreased (Chen et al. 2012).

As shown in Fig. 4 (b), with the increase of CSW loading from $0 \%$ to $50 \%$, the opacity of softwood pulp paper increased gradually. The rising mechanism can be understood that unfilled paper is made up of fibers and air (existing between the fiber pores). When the light beam hits the surface of the paper, part of the light is scattered on the fiber-air interface and gives the paper a certain (lower) opacity because the refractive index of the fiber and air is different. After adding fillers with a refractive index greater than cellulose to paper, rigid mineral fiber fillers and flexible wood fibers form a three-dimensional structure of interwoven fabrics (Wang et al. 2010). The number of light scattering interfaces inside the paper is increased, that is, fibers and air, fillers and fibers, and fillers and air. Among three interfaces, the difference between the refractive index of the filler and the air is large. Therefore, the maximum scattering of light at the filler-air interface results in increased opacity (Bi et al. 1995).

As shown in Fig. 4 (b), the opacity of the bleached wheat straw pulp paper samples changed significantly after CSW was added, but there were obvious differences compared with that of softwood pulp. When the amount of CSW increased from $0-30 \%$, the opacity of the bleached wheat straw pulp paper gradually increased. The change trend of opacity of softwood pulp is opposite to that of wheat straw pulp. However, when the filling amount of CSW is $30 \%$, considering the retention rate of CSW as shown in Table 4, both softwood and bleached wheat straw pulp have the best opacity effect. The reason is that the difference of fiber morphology and surface potential between wheat straw pulp and softwood pulp determines the filling mode of fillers, the bonding state between fillers and fibers, and the bonding tightness between fibers. The fiber of bleached wheat straw pulp is shorter than that of softwood pulp, and the potential of bleached wheat straw pulp is unstable, which affects the bonding strength between fillers. The addition of a large number of CSW destroys not only the bonding between the fibers but also the optical uniformity of the medium in the paper. In addition, the binding between the fibers of wheat straw pulp is more relaxed than that of softwood pulp, and the filler particles are easier to flocculate in wheat straw pulp. The flocculation between filler particles increases the optical contact of particles and reduces the light scattering interface (Chen. 2011).

\subsubsection{Changes of pH value of softwood pulp and bleached wheat straw pulp after adding CSW}

As is shown in Fig. 5, the pH of paper was affected by the addition of CSW in softwood pulp, but the effect was not obvious. The $\mathrm{pH}$ of the paper decreased only 0.1 with the increase of the filling amount from $0-40 \%$. With the increase of mass fraction, CSW shows stronger acidity (as shown in Table 3) (Liu et al. 2004). Therefore, adding appropriate amount of CSW will reduce the $\mathrm{pH}$ of the base paper. However, when the filling amount is more than $40 \%$, the pH of the paper is maintained at 8.05 around. This may be related to the solubility of CSW. After the solubility is saturated, it will not be redissolved even if it is refilled. Furthermore, it no longer affects the change in $\mathrm{pH}$ of the paper.

It can be seen from Fig. 5 , the $\mathrm{pH}$ of the paper remains unchanged at 8.1 when the CSW filling amount in bleached wheat straw was less than $30 \%$. After the wheat straw pulp was bleached, a small amount of 
organic acids and bleaching residues were present. When a small amount of weakly basic CSW was added, a neutralization reaction with its residual acid and bleach occured. So the $\mathrm{pH}$ of the paper did not change as expected. When the filling amount was more than $30 \%$, the $\mathrm{pH}$ of the paper decreases from 8.1 to 7.9 with the increase of the filler.

It is found that the change among the amount of CSW loading has a certain correlation with the change of the $\mathrm{pH}$ for the paper, while it remains in the weak alkaline range.

\subsubsection{Effect of CSW filling on paper uniformity}

As shown in Fig. 6, when the amount of CSW was 30\%, the uniformity index of softwood pulp reached 240. It showed that CSW has the highest retention rate of $71.45 \%$ in the paper (Table 4). The network structure of whisker and plant fiber in the paper is better than that in other filling cases. And the dispersion of CSW in the paper is the best. The internal charge is dispersed evenly, the arrangement of fillers and fibers is good, the fiber flocculation phenomenon is less, and the quality of printed matter printed with this kind of paper is also relatively good. On the other hand, when the CSW was mixed with bleached wheat straw pulp, the evenness of the paper decreased slightly compared with that without filling. Because the fiber morphology and strength of bleached wheat straw pulp are different from those of softwood pulp (Yang. 2005), after large amount of CSW is filled, the charge dispersion is uneven and the charge groups are over-concentrated, resulting in serious fiber flocculation and the decrease of paper evenness (Han. 1993).

\subsubsection{Changes in the Z-direction tensile strength and surface strength of the paper after CSW filling}

As shown in Fig. 7 (a), with the increase of CSW, the Z-direction tensile strength of softwood pulp and bleached wheat straw pulp paper showed different tensile trends. The Z-direction tensile strength of softwood pulp paper reaches the maximum value of 182 when the filling amount is $10 \%$. CSW has a strong charge adsorption capacity in the papermaking process. It can absorb a large amount of positively charged electrolyte and bridge with negatively charged fibers, thereby improving the Z-direction tensile strength of the paper (Ma. 2015; Cheng et al. 2014). However, as CSW continues to be filled, additional CSW replaces some plant fibers, which destroys the original bonding state between paper fibers and creates a "steric hindrance effect" (Li. 2019). In particular, the two filling methods "inlay" and "expansion" in Fig. 1 further hinder the cross-linking and hydrogen bonding between fibers (Jiang et al. 2008). Unlike softwood pulp,the Z-direction tensile resistance increased quite a lot when the bleached wheat straw pulp paper is filled with more than $30 \%$, the fiber and CSW form a strong skeleton structure due to the "reinforced concrete" effect among fibers, larger voids and CSW, which improves the mechanical properties of the paper and plays a role in increasing the Z-direction resistance of the paper (Liu. 2010).

Figure 7 (b) (c) shows the changes in the surface strength of paper (softwood pulp and bleached wheat straw pulp) before and after CSW filling. There was no obvious surface fluff when filling amout was less than $20 \%$ for both types of paper, while they have obvious surface fluffing after filling more than $40 \%$, as shown in Fig. 7 (b)-A, B, C, 7 (c)-E, F. It can be seen that filling amount accounts for the main reason of 
surface strength, nevertheless with higher filling amout, the hydrogen bonding of the fiber itself, and the adsorption bond between the CSW and the fiber is broken due to the "sandwich" structure between the fiber and the CSW (Wei et al. 2012). However, compared with softwood pulp paper, the fluff phenomenon of bleached wheat straw pulp paper appeared earlier at $30 \%$ filling amount. The reason is related to the bond strength between the fibers of the wheat straw pulp itself. After bleached, the supramolecular structure of the fiber is affected to varying degrees under the action of the bleaching agent. And the fibers inevitably undergo alkaline hydrolysis and peeling reactions, and the hydrogen bonds between the fibers are destroyed, which in turn weakens the bonding strength between the fibers following with the occurrence of powder-falling, fluffiness, and whitening of paper (Meng. 2014).

\section{Conclusions}

In this study, the effects of CSW with different raw materials on the printing performance of paper were analyzed and compared.

CSW has many excellent physical and chemical properties, such as high whiteness, low solubility, high retention, acid and alkali resistance, good infrared reflectance and easy surface treatment.

In the contrast experiment of filling different materials, the overall trends of whiteness, acidity, alkalinity, and surface strength on paper printing performance are consistent, whether it is coniferous pulp or bleached wheat straw pulp with CSW on the printing performance of the paper, in addition to the difference in the opacity and the Z-direction tensile strength of the paper. However, the effect of softwood pulp filling on paper printing performance is better than that of bleached wheat straw pulp filling.

In the comparison test before and after the paper filled, the whiteness, opacity, Z-direction tensile strength, and surface strength of the raw materials after adding CSW was significantly improved, which improved the printing adaptability. Due to the whiteness and electrostatic adsorption of the filler, CSW is suitable as fillers for printing papers in order to require high whiteness, opacity and strength. But the improvement of printability in acidity, alkalinity and uniformity is not obvious.In summary, as an inorganic mineral filler, CSW has good paper-forming properties and can replace some fibers for papermaking, thereby reducing the use of paper-making raw materials.

\section{Declarations}

\section{Acknowledgements}

This project was supported by National Natural Science Foundation of China (No.31700516), Special Project No.2017YFB0307901 in the National Key Research and Development Program of China『and the Foundation of Tianjin Key Laboratory of Pulp \& Paper (No. 202005), The Project program of Key Laboratory of Food Nutrition and Safety, Ministry of Education \& Tianjin Key Laboratory of Food Nutrition and Safety, China (No. TJS202001) 
Conflicts of interest/Competing interests: No

\section{References}

Zhu Y (2005) Types and Characteristics of Papermaking Fillers. Shanghai Papermaking36: 36-41.

Liu S, Zhang X, Luo J, Pang Y (2010) Application of Mineral Materials in Paper Industry. Modern Mining: 491: 26-27.

Srivabut C, Hiziroglu S (2018) Effect of nanoclay, talcum, and calcium carbonate as filler on properties of composites manufactured from recycled polypropylene and rubberwood fiber. Construction and Building Materials 162: 450-458. 10.1016/j.conbuildmat.2017.12.048

Wu Y, Zhao C, Han W, Jiang Y, Han W (2016) Study on Modified Calcium Carbonate Used as Paper Filler. Proceedings of the 2016 National Special Paper Technology Exchange Conference and the 11th Annual Meeting of the Special Paper Committee: 265-268.

Rajamuneeswaran S, Vairamuthu J, Nagarajan S, Jayabal S (2020) A comparative study on mechanical properties of coir fiber reinforced polymer composites filled with calcium carbonate particles.

Materialstoday: PROCEEDIGS. 10.1016/j.matpr.2020.08.366

Gendy A, Khiari R, Bettaieb F, Dufresne A (2014) Preparation and application of chemically modified kaolin as fillers in Egyptian kraft bagasse pulp. Applied Clay Science: 626-631.

$10.1016 /$ j.clay.2014.09.032

Gu W (2019) A Novel Paper Filler Silica \& Titanium Dioxide Nanocomposite. World of Consumables 63.

Ketegenov T, Tyumentseva O, Khan N, Myrzabekova M (2019) New composite fillers on the base of flyash cenospheres modified with titanium dioxide. Materialstoday: PROCEEDINGS 128-131.

10.1016/j.matpr.2019.03.080

Wu J (2016) Research on Shell Powder as a Filler for Papermaking. Dalian University of Technology.

Rui Y (2012) Application of attapulgite clay functional filler in papermaking. Lanzhou University of Technology.

Chang J (2014) Modification of wollastonite and its application in paper industry. Qingdao University of Science and Technology.

Shi Y, Xie L (2000) A New Papermaking Material: Gypsum Microfiber. Southwest Papermaking 29, 18.

Mao C (2006) New Technology for Wet Production of Phosphoric Acid and CSW. Inorganic Salt Industry 3: $51-53$.

Chen X, Cui B, Yin J (2007) Application of CSW in Papermaking. Heilongjiang Papermaking 2: 4-5. 
Shen J, Song Z, Qian X (2007) Research Progress of Paper Filling Engineering and New Fillers. Journal of China Papermaking 22: 113-119.

Lu Z, Gao Y, Liu H, Li M (2010) Preliminary Study on Application of PhosphogypsumWhiskers in Papermaking. Journal of Tianjin University of Science and Technology 25:35-37.

Su W (2003) Prospects for Comprehensive Utilization of Phosphogypsum. Jiangxi Chemical Industry 4: $21-24$.

Yin T, Yang X, Yang X, Sun H (2008) Application of gypsum mineral fiber in papermaking and its market prospects. China Non-Metallic Mining Industry Herald.

He B, Zhang C, Wu H, Chen Y (1999) Preliminary Study on Zeta Potential Analysis of Pulp Suspension. China Papermaking Journal.

Lu Z (2010) Study on the Application of CSW in Papermaking. Tianjin University of Science \& Technology.

Freyer D, Voigt W (2003) Crystallization and phase stability of $\mathrm{CaSO}_{4}$ and $\mathrm{CaSO}_{4}$-based salts. Monatshefte Fur Chemie 134: 693-719.

Lv P, Fei D, Dang Y (2013) Research Progress in Preparation of Calcium Sulfate Whiskers with Phosphogypsum and Whisker Paper Application. Progress in Chemical Industry.

Shiel L (1979) Preflocculated filler compositions for use in the manufacture of paper, US: 4174998.

Chen X, Cui B (2006) Application of CSW and Natural-CSW in Papermaking. Southwest Paper 5: 31-32.

Yang R, Song X (2012) Research on purification of phosphogypsum and preparation of calcium sulfate whisker. Inorganic Chemicals Industry 44: 31-34.

Chen H (2012) Effects of Fillers and Dyes on the Phase and Whiteness of Inkjet Primary Paper. China Paper Industry 16: 45-48.

Wang S, Jiang X, Chen F, Chen X (2010) Application of inorganic mineral fiber compound filler in papermaking. Journal of Qingdao University of Science and Technology (Natural Science) 31: 376-379.

Bi S et al (1995) Light Scattering Coefficient of Unfilled and Filled Paper. Journal of China Paper Industry S1: $54-60$.

Chen Y (2011) Science of Printing Materials. Beijing: China Light Industry Press.

Liu X, Chen Y (2004) Effect of Paper Uniformity on Printing Performance. International Paper.

Yang S (2005) Plant Fiber Chemistry. Beijing: China Light Industry Press. 
Han Q (1993) The Effect of Starch on the Evenness of Thin Paper. Paper and Paper 4: 40.

Ma Q (2015) A Brief Discussion on the Effect of CSW Filling on the Properties of Thin Paper. Hunan Paper 4: $23-24$.

Cheng Y, Jiang Q, Wei R, Zhao M (2014) Non-polar modification of gypsum whisker surface and application of papermaking filler. East China Paper.

Li L (2019) Influence of filler aggregate morphology and distribution characteristics on paper properties and its regulating mechanism. Shaanxi University of Science \& Technology.

Jiang L, Zhao Z, Yang D (2008) Effect of paper whiteness on print quality. Packaging Engineering 29: 6668.

Liu Y (2010) Preparation of CSW and its application in papermaking. Northeast Forestry University 35.

Wei X et al (2012) Physicochemical properties of new calcium silicate fillers and their effects on the performance of filled paper. Paper Chemicals.

Meng Q (2014) Research on the effect of reuse and chemical technology on fiber properties and its mechanism. South China University of Technology.

\section{Figures}

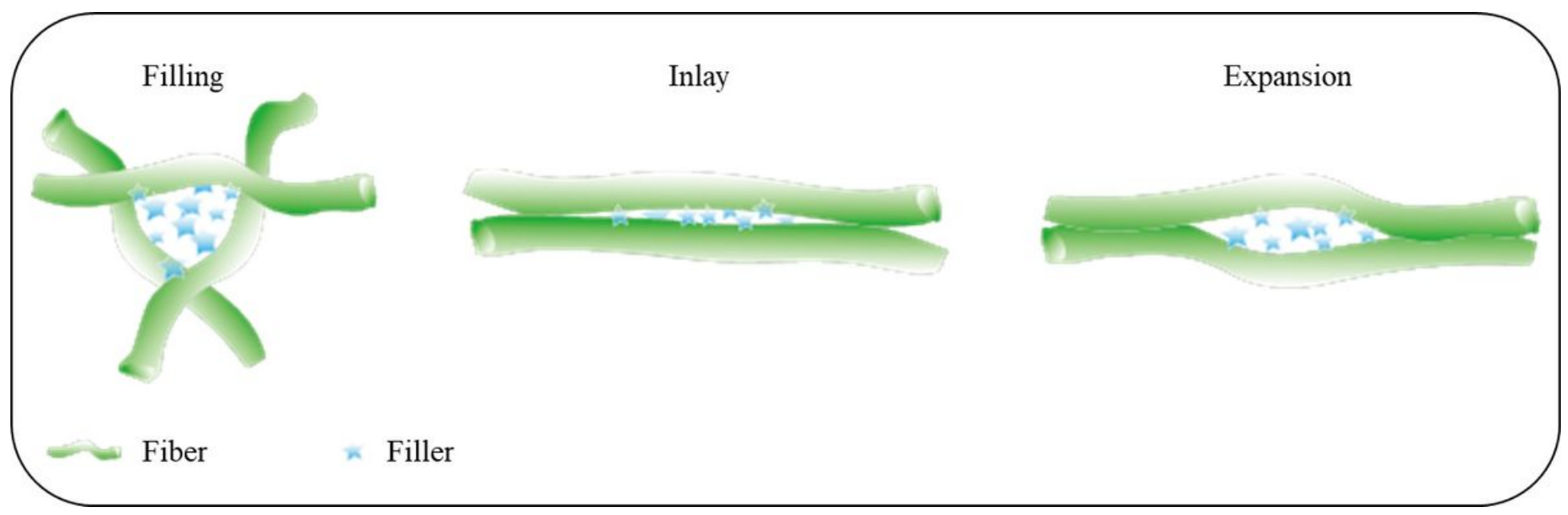

\section{Figure 1}

Filler filling methods in papermaking process. 


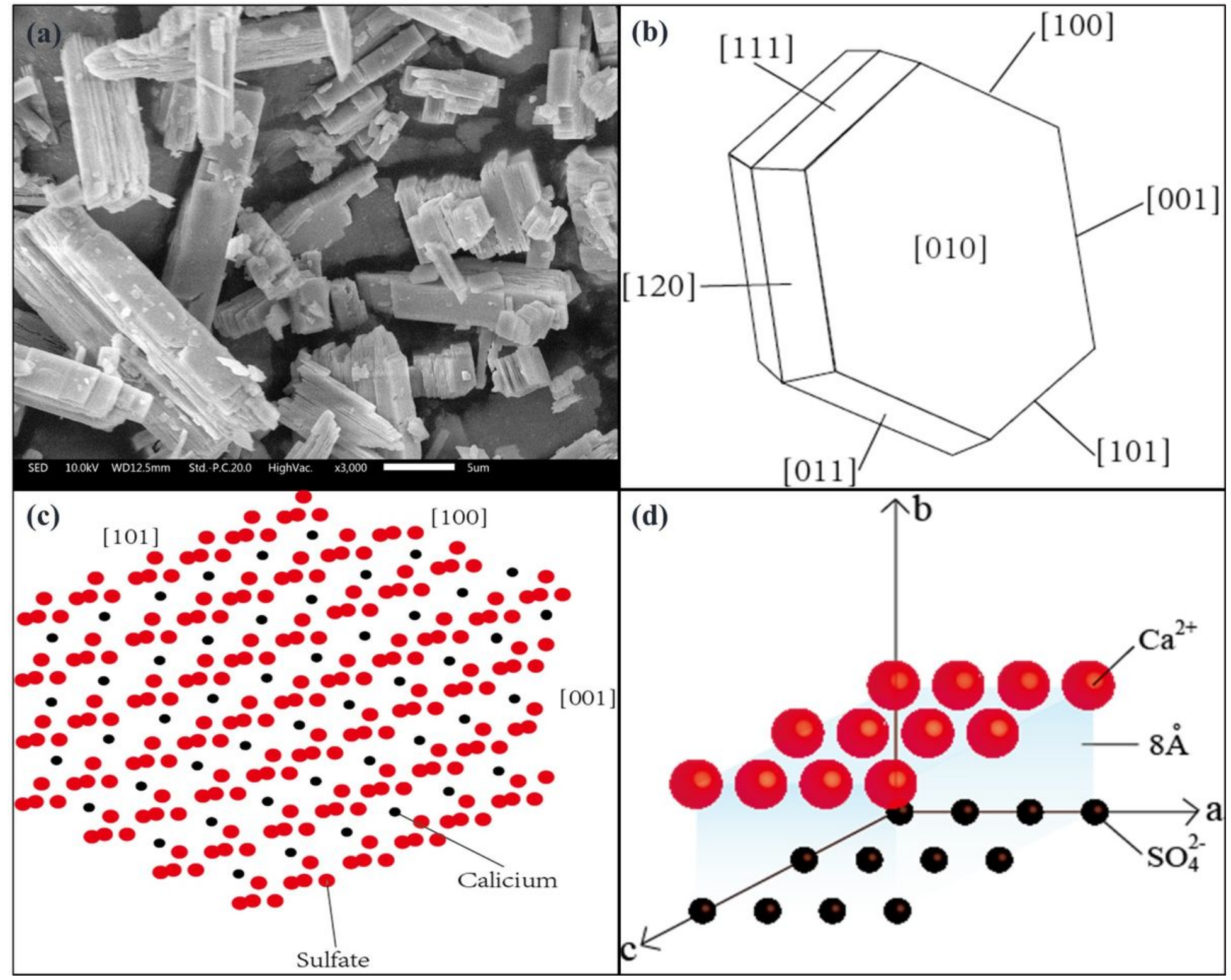

Figure 2

Structure diagram of CSW. 


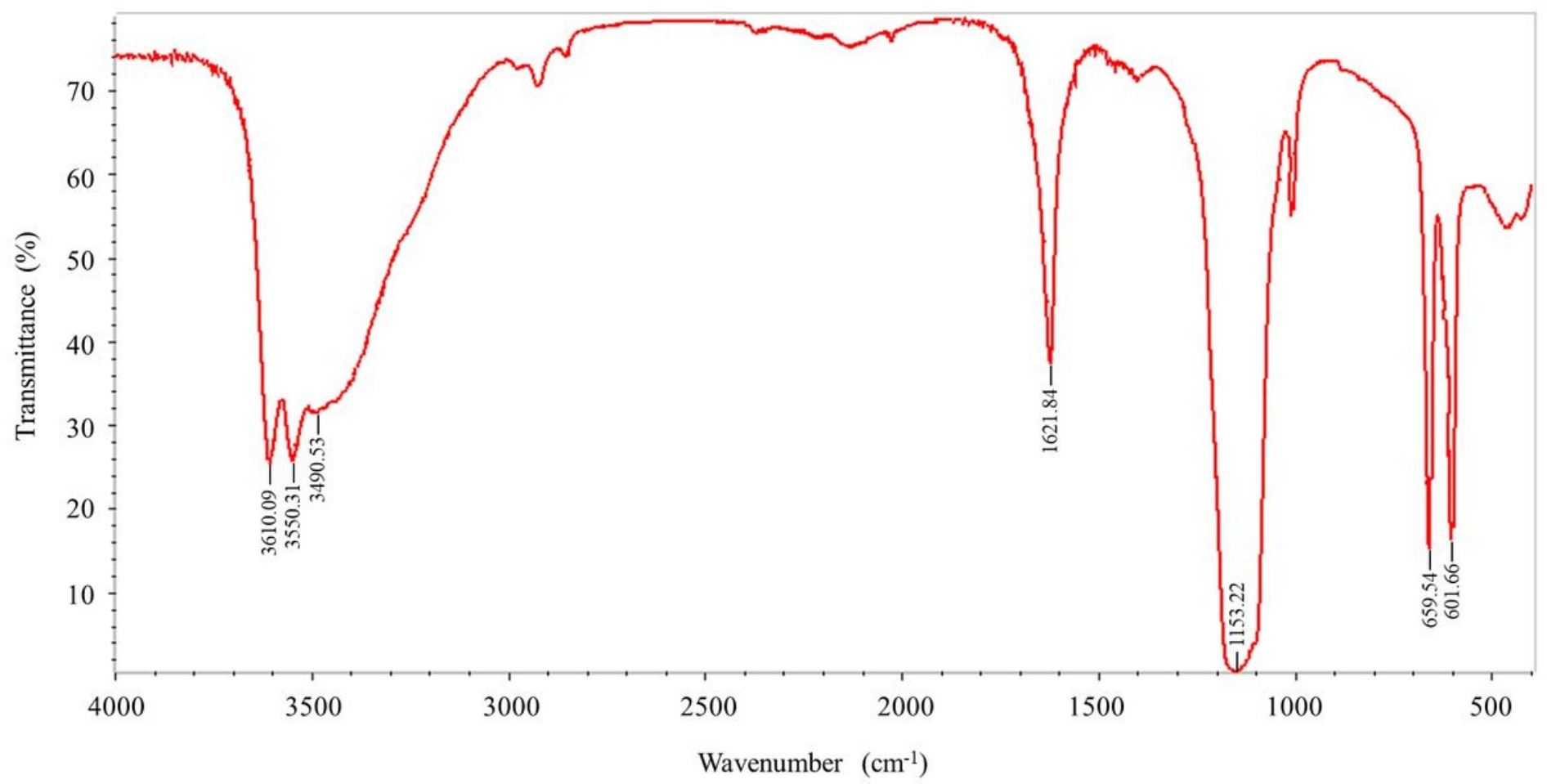

Figure 3

Fourier Infrared Spectroscopy. 


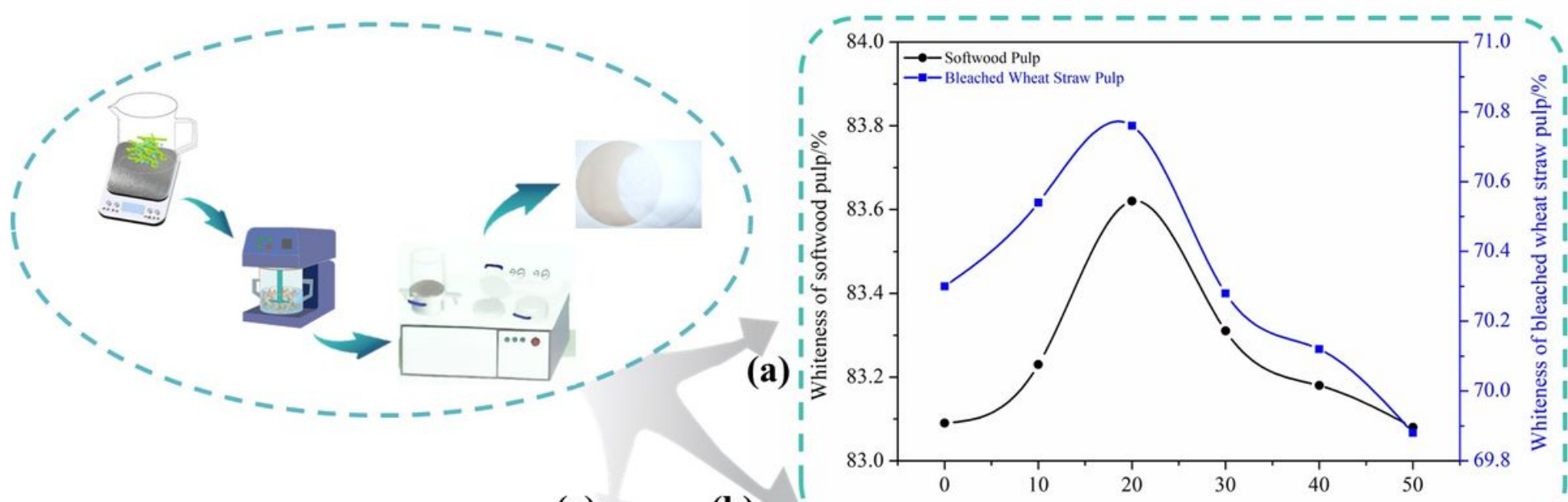

(c) (b)

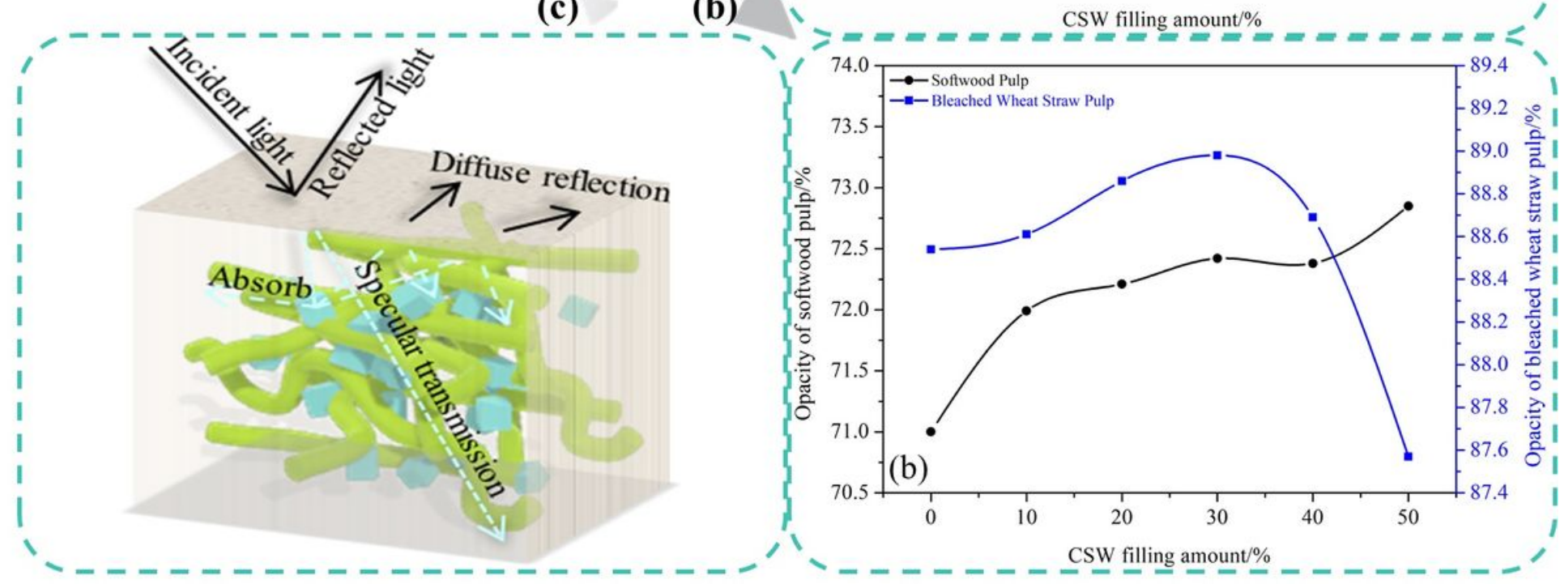

Figure 4

The change trend of whiteness and opacity before and after paper filling. (a) Changes in paper whiteness. (b) Changes in paper opacity. (c) Mechanism of Paper Opacity. 


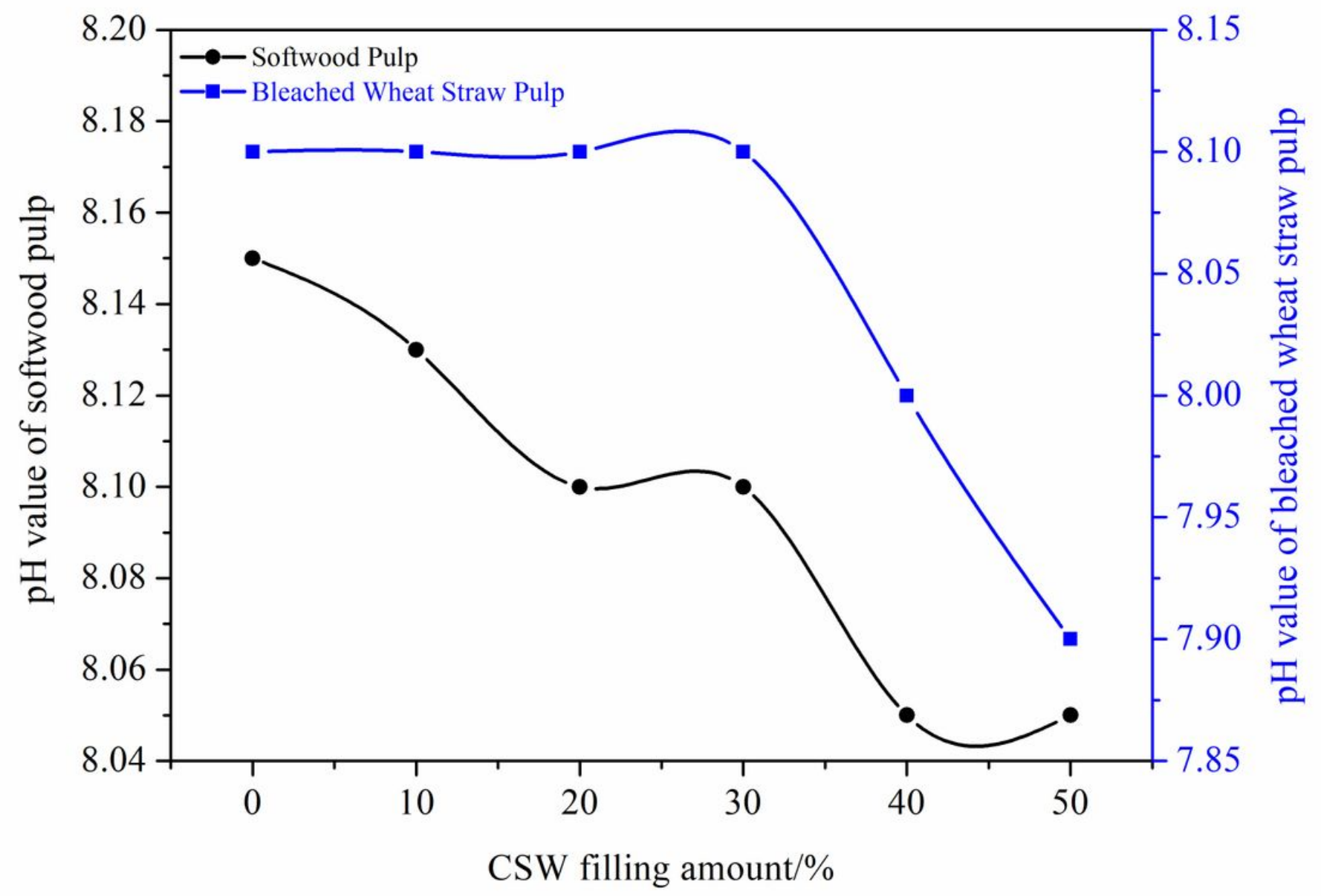

Figure 5

The change trend of $\mathrm{pH}$ value before and after paper filling. 


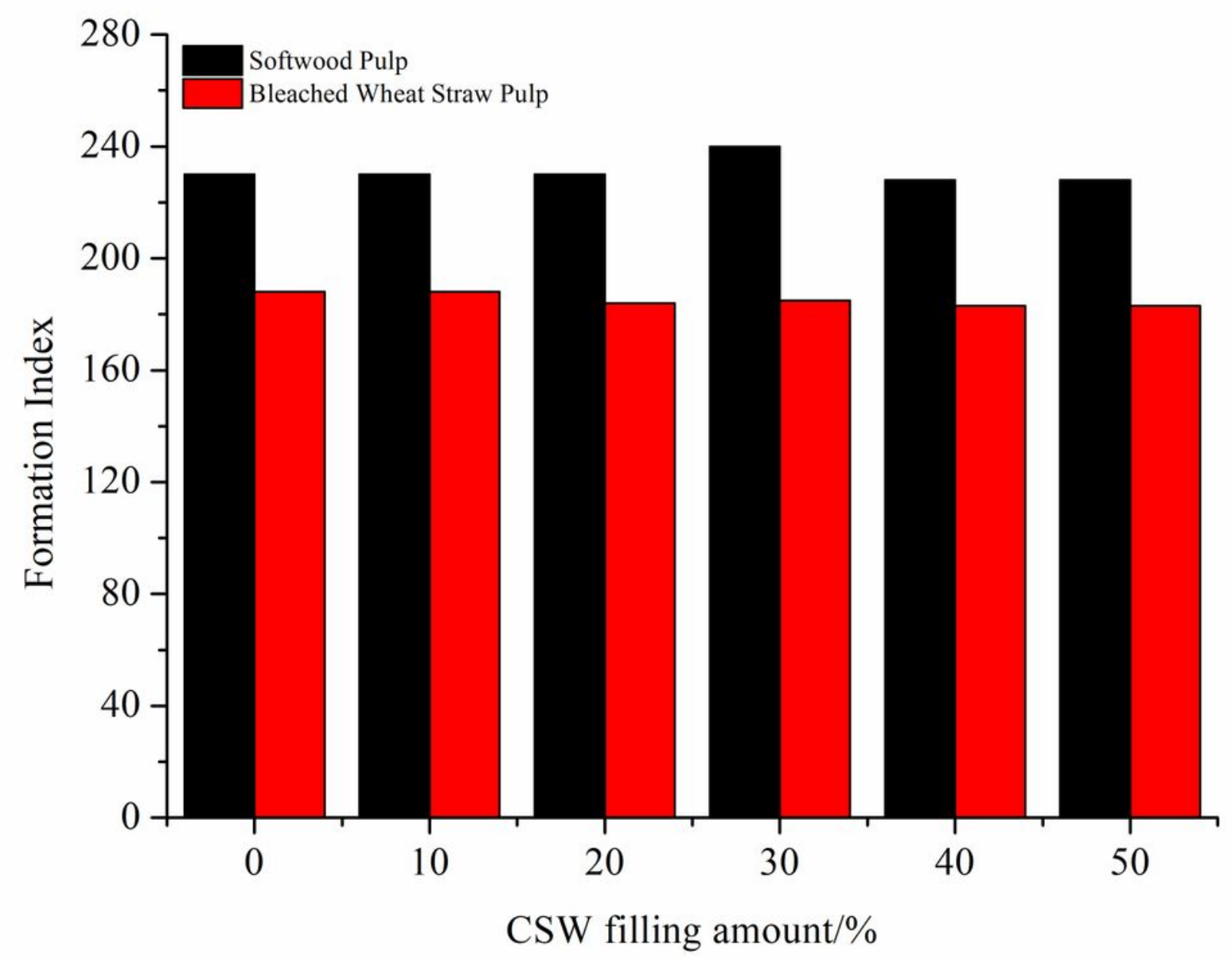

Figure 6

Changes in paper uniformity after adding CSW. (The beating degree of softwood pulp is $30^{\circ} \mathrm{SR}$, and that of bleached wheat straw pulp is $30^{\circ} \mathrm{SR}$.) 

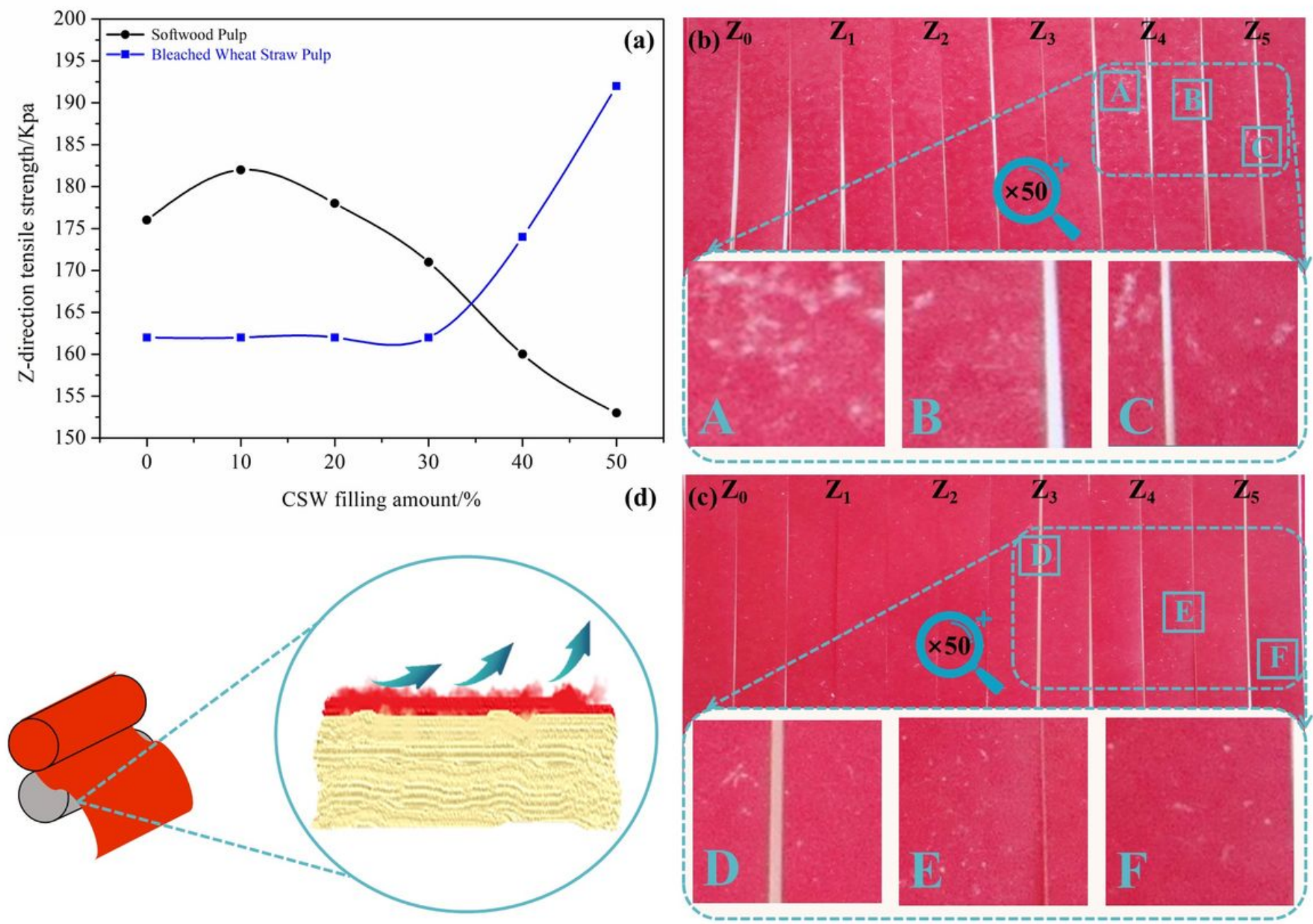

Figure 7

Change of Z-direction tensile strength and surface strength of paper after CSW filling. (a) The change in Z-direction tensile strength varies with the amount of CSW added. (b)\&(c) Changes in surface strength of softwood pulp and Bleached Wheat Straw Pulp. (Z0 means: CSW filling amount is $0 \%$; Z1 means: CSW filling amount is $10 \%$; the rest is analogized.) (d) Paper fluffing observed from the cross section of the paper.

\section{Supplementary Files}

This is a list of supplementary files associated with this preprint. Click to download.

- GraphicalAbstract.jpg 